\section{Original Article}

\begin{tabular}{|l|}
\hline Access this article online \\
\hline Website: \\
www.ajobe.org \\
\hline DOI: \\
10.4103/1817-7417.86040 \\
\hline Quick Response Code: \\
\hline \\
\hline
\end{tabular}

Address for Correspondence: Prof. Marilise Smurthwaite, St Augustine College of South Africa, PO Box 44782 Linden South Africa 2104.

Email:m.smurthwaite@ staugustine.ac.za

\title{
Business Ethics as field of training, teaching and research in Southern Africa
}

\section{Marilise Smurthwaite}

Head of Department, Applied Ethics, M. E. Smurthwaite. St Augustine College of South Africa, 53 Ley Road, Victory Park 2195. South Africa.

\section{ABSTRACT}

Few studies have been done on Business Ethics as field of training, teaching and research in Southern Africa. This article details the methodology and findings of the survey of Business Ethics in Southern Africa. Findings, among others, indicate the preferred terminology used to refer to the field of Business Ethics. It also shows that most expertise in the field is found in South Africa, centered mainly at the meso-economic level, with most research being done on CSR, corporate governance and economic justice. Future challenges identified for the field of Business Ethics are mainly at the macro-level, especially related to the economic system and ecology where little research or expertise is currently focused.

Key words: Business Ethics, Teaching, Training, Research, Southern Africa

\section{INTRODUCTION}

The Global Survey of Business Ethics as field of Teaching, Training and Research included nine world regions, which were divided into sub-regions. Southern Africa was one of four sub-regions in the Sub-Saharan region. This article details the methodology and findings of the survey, as well as giving an overview of the sub-region and the existing literature on Business Ethics as field of teaching, training and research in Southern Africa.

\section{OVERVIEW OF THE SOUTHERN AFRICAN SUB-REGION}

The countries included in this sub-region were: Angola, Botswana, Lesotho, Malawi, Mauritius, Mozambique, Namibia, South Africa, Swaziland, Zambia, Zimbabwe.

This sub-region has a combined population of over 148 million and is characterized by a great diversity in languages. While our questionnaire was in English, which is the official language of some of the countries (e.g. Zambia; Namibia), a country like South Africa has 11 official languages, of which English is one. In Zambia, in addition to English, there are 70 other languages used. In countries like Malawi and Mauritius, English is one of the languages used. Electronic communication still poses challenges in some countries in the sub-region, as will be explained in this article.

\section{EXISTING LITERATURE ON BUSINESS ETHICS AS A FIELD OF TEACHING, TRAINING AND RESEARCH: 1995-2010}

The existing literature on Business Ethics as field of Teaching, Training and Research consists of a study by Milanzi (1997) focusing on Eastern and Southern Africa; a study by Rossouw (1997) focusing on South Africa; a Masters' thesis by Barkhuysen (1999) focusing on Africa, a journal article by Barkhuysen and Rossouw (2000) based on the said thesis and an unpublished study on teaching Business Ethics at three South African universities by Woermann and Hattingh (2009).

Milanzi's study (1997) found an information deficit in the field of Business Ethics. Business in Eastern and Southern Africa saw ethics "as a necessary condition for profitable business management" (1997: 1550) while governments acknowledged the destructive economic effects of corruption and issued various laws and policies related to Business Ethics. The study found no agreement on terminology for Business Ethics. In academia, most institutions of higher learning had no Business Ethics although Milanzi makes an unsubstantiated claim that $65 \%$ of these had business centres, established to deal with 
issues relating to Business Ethics, although these were in the early stages. While some Business Ethics issues were dealt with in law departments or specialized units, no Business Ethics was taught as a separate subject. Instead, Milanzi claims that in 15 countries, Business Ethics was included in Commercial, Law or Management courses though these were not substantive inclusions. Very little research, consultancy or publication had been done, although there were some studies or publications on organizational culture, Business Ethics, legal norms and alterations in pricing behavior in respect of trade liberalization (1997: 1552). Research and consultancy were generally focused on managerial problems or organizational constraints rather than on Business Ethics (1997: 1552). There were a few workshops/seminars/conferences/symposia in the private and government sectors that discussed ethical issues, but there was little cooperation between business and academic institutions.

Rossouw's study (1997) found Business Ethics was part of the theoretical and practical landscape in South Africa but there was little reflection on Business Ethics as academic field as such. Politicians, academics and business leaders agreed on the need for Business Ethics and were aware of corruption. 'Business Ethics' was the most widely used term used to refer to the field of Business and Economic Ethics, and both academics and business leaders focused on normative rather than meta-ethical issues. The ethical issues that were identified by business and academia as most pertinent, reflected the South African context at the time. The most important were: building a moral business culture, affirmative action, work ethic and improved productivity, information security and the relationship between business and society. Less important issues were worker participation, decision making, development of ethical codes, bribery and moral decision making. At tertiary institutions, teaching of Business Ethics varied considerably. At universities, Business Ethics could be compulsory, elective, not exist at all or be integrated into subjects like marketing, human resources and strategic planning. Integration of Business Ethics into curricula was either formal or informal. Informal integration was the most common approach meaning Business Ethics was supposed to "happen" on its own, without Business Ethics expertise. In some cases, and to a limited extent, Business Ethics was also taught by departments such as Philosophy. All technikons incorporated a Business Ethics component in the Business Management course. Most research in Business Ethics was done as part of an MBA or other degree, and not in specialized Business Ethics degrees. Between 1987 and 1995, there were 64 articles and 7 books published on some or other aspect of Business Ethics. Very limited cooperation existed between academia and the private sector and was mainly confined to academics teaching the Business Ethics component of corporate training programmes and some consultancy to develop codes of ethics.
The journal article by Barkhuysen and Rossouw (2000), based on the Master's thesis by Barkhuysen (1999), deals with the way in which the academic field of Business Ethics has been institutionalized in Africa (2000: 230) as well as the strengths and weaknesses of Business Ethics as academic field. Most literature and reflection on Business Ethics was either of European or North American origin, with no comprehensive picture of Business Ethics in Africa emerging at the time due to the young nature of the field in Africa. This study noted two views on the central focus of Business Ethics, one being that it studies the ethical dimensions of business; the other, that it improves the behavior of those in business. Most attention was focused on prescriptive ethics, followed by descriptive ethics, mostly at the micro and meso levels. Little attention was given to the macro-ethical level or to meta-ethics. Teaching of Business Ethics was found in 6 African countries viz. Egypt, Ghana, Kenya, Nigeria, Uganda and South Africa. 77 courses were found, 55 being undergraduate and 22 postgraduate, within 40 departments or business schools at universities in these 6 countries. While there were more courses at undergraduate than at postgraduate levels, most were part of another course in a host discipline such as Human Resources, Business Management, Philosophy etc. These courses were also focused on the micro- or meso-levels and were normative or descriptive. The study found 130 articles and 37 books, i.e. a total of 167, with most articles originating in South Africa, followed by authors not resident in Africa, followed by Kenya, Uganda and Nigeria. Research was largely focused on descriptive or normative issues with little attention being paid to meta-ethics. Most research focused on the micro-level, followed by the meso-level, with little at the macro-level. Professional associations and interaction were evidenced by 7 centres (in Kenya, Nigeria, South Africa, and Uganda) and 4 institutes (in Egypt, South Africa and Uganda) which dealt with Business Ethics largely from a normative perspective. None had Business Ethics as its total focus. In addition, there was the BEN-AFRICA network and 6 conferences/seminars which had been held in Kenya, South Africa and Uganda. The study concluded that Business Ethics was an emerging academic field in Africa, with most activity being in South Africa. It recommended further study on Business Ethics as academic field and highlighted the lack of African case studies.

Woermann and Hattingh's unpublished study (2009) (permission to refer to this granted by Woermann) is a comparative study of teaching methods in Business Ethics. Its goal was to identify current strengths and challenges so as to propose guidelines for teaching Business Ethics. The study aimed to discover what students thought about content and teaching strategies of applied ethics courses in accounting programmes and how teaching strategies could be improved. It compared experiences across 3 prominent universities using interviews with lecturers and a survey with students for purposes of data collection. As it is not 
yet published, findings, conclusions and recommendation will not be detailed here.

\section{METHODOLOGICAL CONSIDERATIONS}

The research objectives and methodology for this study are identical to those of the African Survey of Business Ethics discussed by Rossouw in the first article of this special issue, but are applied, in this instance, specifically to the Southern African sub-region. The methodological considerations for this region are as follows:

\section{Research process and methodology}

To conduct the research the following process was followed:

- Selection of research team: Potential team members received email invitations in February 2009. Names had been selected from the BEN-Africa address list and from contacts of the sub-regional coordinator in order to have team members in each country in this sub-region. Unfortunately, this proved impossible due to poor response to the invitation. The team selected from available responses comprised six South Africans, two Zimbabweans, one member in Botswana and one in Lesotho. All research team members were volunteers and some proved more able than others to obtain the required information. This proved to be one of the constraints in the methodology.

- Allocation of areas: The sub-region comprised of Angola; Botswana; Lesotho; Malawi; Mauritius; Mozambique; Namibia; South Africa (divided into Gauteng, Natal, Western Cape, Eastern Cape, Northern Cape, Free State, North West Province, Mpumalanga and Limpopo); Swaziland; Zambia and Zimbabwe. Particular areas were allocated to each of the research team members.

- Stage 1: Identifying and contacting potential survey participants: In March 2009, team members were sent relevant documents to assist them to identify individual and institutional expertise in Business Ethics as defined for survey purposes.

- Stage 2: Data collection: Individuals and institutions were requested to complete the relevant questionnaire, either online at the globethics.net website, or electronically by email or in hard copy. Unfortunately, contact with potential participants did not necessarily translate into completed questionnaires. The online version was technically difficult for some participants and some did not return questionnaires. In addition, contact with certain research team members to ascertain if or what information they had acquired, proved difficult. Of the ten research team members, six submitted details of persons and institutions contacted or problems experienced in contacting persons. Actual contacts as at September 2009 are indicated in Table 1.

Of the individual questionnaires that were distributed, 18 were returned, and of the institutional ones, 4 were returned.
Table 1: Contacts of institutions/individuals by September 2009

\begin{tabular}{lcc}
\hline Area & $\begin{array}{c}\text { Number of institutions } \\
\text { contacted }\end{array}$ & $\begin{array}{c}\text { Number of individuals } \\
\text { contacted }\end{array}$ \\
\hline Eastern Cape & 4 & 7 \\
KwaZulu-Natal & 5 & 8 \\
Western Cape & 3 & 11 \\
Gauteng & 59 & 59 \\
Lesotho & 1 & 2 \\
Total & 72 & 87 \\
\hline
\end{tabular}

*Note that many of the 59 institutions approached in Gauteng, were not academic institutions or ethics centres per se, but included a variety of enterprises in an attempt to establish where and how Business Ethics teaching and research might be found

As a consequence, data also had to be collected by means of desktop searches of universities and other educational institutions' websites to ascertain whether Business Ethics was addressed in these institutions. Electronic addresses were obtained from the World of Learning database. Table 2 gives the results of these searches.

As indicated in this table, in certain areas websites were unavailable or fairly basic, thus hampering searches. Other useful sources of data, particularly for evidence of publications and research in the field, were desktop searches of known authors and the use of database analysis. The latter included the Africa-Wide: NiPAD database. The St Augustine College library also provided useful information on Masters and Doctoral research done at this institution.

Stage 3: Data analysis: This stage of the research process involved analysis of all data by the sub-regional coordinator. Data included questionnaire responses exported from the centralized databank in Switzerland and all data from desktop and database searches. Data relating to each main area of the questionnaire was sorted into themes and categories were refined. Below the findings that emerged from the data-analysis are reported.

\section{FINDINGS FOR THE SOUTHERN AFRICAN SUB-REGION}

\section{Terminology and conceptualization of Business Ethics}

Individual questionnaires indicated that the term 'Business Ethics' is most commonly used in English to refer to the field of Business and Economic Ethics, while the Afrikaans (an official language in South Africa) terms most commonly used are 'Sake-etiek' and 'Besigheidsetiek' (both translated as Business Ethics). Institutional questionnaires indicated terms used were: 'Professional Ethics' (or 'Professionele Etiek' in Afrikaans), 'Business Ethics' (or 'Sake-etiek' in Afrikaans) and 'Korporatiewe bestuursgedrag' (in Afrikaans, translated as corporate governance). The variety of terms reflected in the individual questionnaires as well as their incidence is summarized in Table 3 below. 


\begin{tabular}{|c|c|c|c|c|}
\hline Area & $\begin{array}{l}\text { No of learning institution } \\
\text { websites searched (some are } \\
\text { universities of technology) }\end{array}$ & Accessible/not accessible & $\begin{array}{l}\text { Evidence of Business } \\
\text { Ethics courses }\end{array}$ & Comment \\
\hline Angola & 3 universities & Not accessible & No & \\
\hline Botswana & 1 university & Accessible & Yes & $\begin{array}{l}\text { No individual questionnaires } \\
\text { were received from Botswana }\end{array}$ \\
\hline Lesotho & 1 university & Accessible & No & $\begin{array}{l}\text { Yet anecdotal information } \\
\text { suggests that there is Business } \\
\text { Ethics at this university }\end{array}$ \\
\hline Malawi & 1 university & Accessible & No & \\
\hline Mauritius & 2 universities & Accessible & No & \\
\hline Mozambique & 3 universities & 2 not accessible & No & \\
\hline Namibia & 1 & Accessible & No & \\
\hline South Africa & 23 & Mostly accessible & Yes & At least at 13 institutions \\
\hline Swaziland & 1 & Accessible & No & \\
\hline Zambia & 2 & $\begin{array}{l}1 \text { inaccessible, } 1 \\
\text { accessible }\end{array}$ & Yes & \\
\hline Zimbabwe & 5 & Accessible & No & $\begin{array}{l}\text { Yet anecdotal evidence } \\
\text { suggests there is Business } \\
\text { Ethics here }\end{array}$ \\
\hline
\end{tabular}

\begin{tabular}{lclc}
\hline \multicolumn{4}{l}{ Table 3: Terminology and conceptualization of Business Ethics: Individuals } \\
\hline English & No.of times mentioned & Afrikaans & No. of times mentioned \\
\hline Business Ethics & 12 (incl. translations) & Sake-etiek & 8 \\
Management ethics & 2 & Besigheidsetiek & 6 \\
Business law and ethics & 1 & Bestuursetiek & 2 \\
Corporate governance and ethics & 1 & Bemarkingsetiek & 1 \\
Economic ethics & 1 & Aankope etiek & 1 \\
Economic and Business Ethics & 1 & & \\
Enterprise ethics & 1 & & \\
Ethics of marketing & 1 & & \\
Ethics of purchasing & 1 & & \\
\hline
\end{tabular}

It is clear that 'Business Ethics' is the most frequently used term, (as also found in Rossouw's 1997 study) followed by 'Sake-etiek' and 'Besigheidsetiek', which are the Afrikaans versions of the English term 'Business Ethics'.

\section{Prevalence and distribution of Business Ethics}

In this sub-region, most expertise and capacity in the field of Business Ethics is concentrated in South Africa, specifically in the Western Cape and Gauteng followed by the Eastern Cape and Natal. Also noteworthy is the apparent lack of Business Ethics expertise in many areas, some of which returned no questionnaires though desktop searches suggested that Business Ethics, even if not referred to explicitly, was incorporated into training or teaching. For example, a desktop search revealed that the University of Botswana, had a short training course "Executive Development Programme for Senior Public Sector Financial Managers" in the Faculty of Business which incorporated concepts like governance, integrity and sustainability and focused on managerial decision making, accountability and ethics "as applied in central and local government departments" (University of Botswana). Other examples of this type of anomaly revealed by desktop searches were courses which included various aspects of Business Ethics taught at North West University, UNISA and University of the Free State, despite no questionnaire returns from individuals at these institutions who have Business Ethics expertise. This suggests, therefore, that there is a greater prevalence, distribution and expertise in Business Ethics than the questionnaire returns, suggest.

\section{Focus areas in Business Ethics}

Focus areas were indicated by both individuals and institutions. Individual focus areas were grouped into four broad themes each of which comprised various subthemes (numbers below indicate the number of times a particular sub-theme was cited as an area of expertise). Most respondents mentioned more than one area of expertise. Note that where the word 'macro-level' is used we refer to systemic issues where the moral focus is on the economic system. Where the word 'meso-level' is used we refer to issues at the organizational level where the focus is the moral responsibility of enterprises to society. Where the term 'micro-level' is used, we refer to issues within the enterprise where the focus is on areas like individual moral decision making on particular issues or 
on internal policies etc. The results of the data analysis were as follows:

- Theme 1: Ethics and Business Ethics including Business Ethics as academic field (3); teaching Business Ethics (3); professional ethics (1); ethical /normative theories (2); rational choice theory (2) (total: 11).

- Theme 2: Ethics at macro-level including globalization (1); global ethics $(1)$; global bioethics (1); ethics and economic systems (2) and economic justice (1); sustainability (1) and environmental ethics (3) (total: 10)

- Theme 3: Ethics at the meso-level including corporate social responsibility (5) social responsibility (1); corporate citizenship (1); catholic social teaching and corporate responsibility $(1)$; governance of corporations (3) and of corporate ethics (1); corporate reporting (1); the corporation (1); corporate agency and identity (2); and the ethics of corporate entities $(1)$; codes of ethics $(1)$; ethics in the workplace (1); organizational ethics $(1)$; creating organizational ethics infrastructure (1); and integrity management (1) (total:24).

- Theme 4: Ethics at the micro-level including ethical business leadership (1); leadership ethics at work (1); unethical business practice: corruption (1) anticorruption (1); corporate misconduct (1) and fraud (1); specific ethics issues or activities such as HIV/AIDS (1); cross-sector collaboration (1); employment screening (1); responsible (ethical) investing (1); and the role of pharmaceuticals especially in the developing world (1); ethics of persuasion (1) (total: 12).

The above information suggests that most expertise and focus centers at the meso-level, particularly in areas like corporate social responsibility, ethics and the corporation and corporate governance. Much less focus is found in themes 1, 2 and 4 and these are fairly equitably represented. That fewer persons focused on ethics at the macro-level and on Business Ethics as academic field, is a similar finding to that of Barkhuysen and Rossouw (2000).

Institutional responses indicated a predominant focus on professional ethics, corporate governance, managing ethics and corruption prevention. The focus once more seemed to be predominantly on the meso-level and on normative rather than on meta-ethics.

\section{Themes in training in Business Ethics}

The main focus of training is ethics in the context of the organization, whether at the meso- or the micro-level. $38 \%$ of training themes focused on organizational ethics, $17 \%$ on unethical behavior and countermeasures, $13 \%$ on ethical dilemmas and decision making, $10 \%$ on governance and ethics and $10 \%$ on ethics as applied to or for particular groups or professions. Only $8 \%$ of training focused on sustainability and only $4 \%$ on theoretical aspects of Business Ethics. Table 4 shows the main themes covered in training and indicates the number of times these were mentioned.

\section{Themes in teaching Business Ethics and elective/ mandatory status of Business Ethics courses}

There were a total of 106 modules in which Business Ethics was taught, 63 at undergraduate level and 43 at postgraduate. At undergraduate level no modules were offered as electives only. Out of 63 modules, 40 were compulsory, with 9 being compulsory and elective and 14 giving no indication of compulsory or elective status. At postgraduate level, of 43 modules, 19 were compulsory, 2 were elective for some students and compulsory for other students, 6 were electives only and 16 were unspecified. At undergraduate level there were 5 main themes to be discerned in the teaching of Business Ethics, while at postgraduate level 4 themes emerged. The themes and number of modules are reflected in Tables 5 and 6 below.

The results above suggest, therefore, that at undergraduate level there is a fairly even balance between modules which give foundations for Ethics, Business Ethics and Applied Ethics; and modules which deal with ethical business issues on the macro-, meso- and micro-levels. It is noteworthy that at undergraduate level most modules are compulsory and that as a single sub-theme/category, CSR and general Business Ethics modules seem to have the most compulsory taught modules. There are no modules which are purely elective: if they are elective for some, they are also compulsory for others. Within the main themes there is diversity, often reflected in one or two courses or modules per sub-theme. CSR is an exception to this, with four compulsory modules.

\begin{tabular}{llc}
\hline Table 4: Themes in training & & Times mentioned \\
\hline Themes & Includes & 18 \\
\hline Organizational ethics & $\begin{array}{l}\text { Managing and developing ethics, ethical workplace culture and } \\
\text { ethical codes, CSR, CSI }\end{array}$ & 8 \\
$\begin{array}{l}\text { Unethical behavior and countermeasures } \\
\text { Ethical dilemmas and ethical decision making }\end{array}$ & $\begin{array}{l}\text { Fraud, corruption, anti-corruption measures, whistle-blowing } \\
\text { Ethics applied }\end{array}$ & $\begin{array}{l}\text { Accountancy ethics, professional ethics, medical ethics, ethics in the } \\
\text { public service }\end{array}$ \\
$\begin{array}{l}\text { Governance and ethics } \\
\text { Sustainability }\end{array}$ & $\begin{array}{l}\text { Sustainable development and reporting, consumer activism } \\
\text { Business Ethics }\end{array}$ & 5 \\
\hline
\end{tabular}


At post-graduate level, the focus differs in some respects from undergraduate with little focus on Business Ethics per se, and less focus on micro-level issues. Most focus is on macro- and meso-levels and on ethics for specific purposes. Fewer modules are compulsory: $31 \%$ at macrolevel, $55 \%$ at meso-level, $29 \%$ at micro-level. However, $60 \%$ are compulsory for the theme Ethics for specific purposes. When compared to undergraduate, postgraduate themes also exhibit a greater concentration of sub-theme content. So, for example, at macro-level, there are 5 modules on the ethics of economic systems and 4 on sustainable development, while in the meso category, there are 7 on corporate governance, 4 on the corporation, but only 2 on CSR. At the micro-level, sub-themes are single instances as in the undergraduate modules. Perhaps these postgraduate findings are cause for concern in that little focus is placed on Business Ethics as academic field, which would surely be important for future research in this area.

\section{Themes in Business Ethics research}

In the Southern African sub-region, a total of 115 research publications were identified for the period 1995-2010, in contrast to the 71 in South Africa identified by Rossouw (1997) and the 167 in Africa identified by Barkhuysen and Rossouw (2000). These Southern African publications could broadly be categorized into 4 main themes and 20 component sub-themes. The main categories comprised theoretical aspects in/of Business Ethics and issues and challenges at macro-level, at meso-level and at microlevel. Each category had several sub-themes which in turn comprised further sub-sub-themes. The sub-themes indicate most research was done in the area of CSR (15\%), corporate governance (11\%) and economic justice/justice (11\%), ethics $(9 \%)$ and social and business issues $(9 \%)$. These were followed by research into Business Ethics (theory, teaching) (8\%). The remaining 14 sub-themes represent $5 \%$ or lower in respect of the total of 115 research publications. Much of the research was done in South Africa, rather than being widely representative of Southern Africa as a whole. This does not necessarily mean there is no research output in other countries, but relates to the fact that all questionnaires returned were from South Africans and most research found on the NiPAD database or library records was also South African. That there is other research in Africa is borne out by a desktop search which revealed that, in the field of international development and policy research, there are some research projects or publications related to the Business Ethics field in Angola and Mozambique, under the auspices of a Norwegian research institute which cooperates with African institutions. A few of these papers/ publications are co-authored by African authors. Topics include Business Ethics for MNCs (1, Angola); CSR (3 Angola), poverty reduction/monitoring (2 Mozambique; 1 Angola), and research areas such as international ethics and global governance. What may be of concern in the Southern African sub-region is that there is little research being done specifically on Business Ethics as academic field, with more being done in areas like CSR, corporate governance and economic justice. Given the South African origin of the research, perhaps this may be seen to reflect 'problem areas' in this country. However, the data per se, gives no empirical indication as to the rationale for areas of research choice. Table 7 presents the sub-themes of the 115 publications, the number and percentage of publications in each sub-theme in descending order, and the main theme area to which each belongs.

Thus $44 \%$ of the research is at the meso-level only, with another $41 \%$ also partly including this level. $20 \%$ includes the macro-level and 25\% the micro-level (latter percentages obtained by adding together percentages in column 3). While these additions would not necessarily be mathematically accurate, they can indicate the main focus of the research and publications, i.e. overwhelmingly at the meso-level. Again Business Ethics, ethics and economic ethics together total only $10 \%$ of the total percentage output.

\section{Major business ethical issues}

The major challenges and issues in the field of Business Ethics over the next 5 years as seen by both individuals

\begin{tabular}{lcl}
\hline Table 5: Themes and numbers of undergraduate modules \\
\hline Theme & Number & Examples of subthemes \\
\hline Business Ethics theory & 16 & Normative ethical theory \\
Ethics for specific professions & 4 & Accounting, financial planning \\
Macro-level themes & 12 & Macro-ethics, Sustainable development, globalization, environmental ethics \\
Meso-level themes & 17 & CSR, corporate governance, managing ethics, codes, ethics and technology \\
Micro-level themes & 14 & Affirmative action, HIV/AIDS, ethical leadership and decision making \\
\hline
\end{tabular}

\begin{tabular}{lcl}
\hline \multicolumn{3}{l}{ Table 6: Themes and numbers of postgraduate modules } \\
\hline Theme & Number & Examples of subthemes \\
\hline Macro-level themes & 13 & Ethics and economic systems, globalization, sustainability \\
Meso-level themes & 18 & Ethics and corporations, CSR, corporate governance, managing ethics \\
Micro-level themes & 7 & Ethical leadership, whistle-blowing, HIV/AIDS, black economic empowerment \\
Ethics for specific purposes & 5 & Auditing, accounting, public service, media workers \\
\hline
\end{tabular}




\begin{tabular}{|c|c|c|c|}
\hline Theme & Number & $\%$ of the total number & Level \\
\hline Corporate social responsibility (CSR) & 17 & 15 & Meso \\
\hline Corporate governance & 13 & 11 & Meso \\
\hline Economic justice/ Justice & 12 & 10 & Macro/meso/micro \\
\hline Ethics & 10 & 9 & \\
\hline Social/business issue & 10 & 9 & Meso \\
\hline Business Ethics & 9 & 8 & \\
\hline Corporations & 6 & 5 & Meso \\
\hline Corporate citizenship & 5 & 4 & Meso \\
\hline Responsible Investing & 5 & 4 & Meso/micro \\
\hline Unethical business practice & 5 & 4 & Meso/micro \\
\hline Economic systems & 5 & 4 & Macro \\
\hline Ethics and Accounting/for accountants/auditors & 4 & 3 & Meso/micro \\
\hline Cultural justice & 3 & 3 & Macro \\
\hline Economic ethics & 2 & 2 & Macro \\
\hline Leadership & 2 & 2 & Meso/micro \\
\hline Ecology & 2 & 2 & Macro \\
\hline Book reviews & 2 & 2 & \\
\hline Human development & 1 & 0.9 & Macro/meso/micro \\
\hline Ethical decision making & 1 & 0.9 & Meso/micro \\
\hline Other & 1 & 0.9 & \\
\hline Total & 115 & 100 & \\
\hline
\end{tabular}

and institutions may be divided into the following three main themes and their component sub-themes (numbers indicate times mentioned)

Macro-level challenges/issues

- The economic system including: the ethics of capitalism (1); ethical approaches to ordering economy (1); the legitimate role of the state in a market driven economy (1); fair trade (3); fair global monetary system (1); reducing the poverty gap between North and South (2) [total: 9].

- Response to the global economic crisis, (2), regulation as a response to this crisis and its implications for business government relations (1); financial ethics (1); governance and codes of conduct at global level (1) [total: 5].

- Environmental and human rights issues including: climate change (4); commercialization of the commons (1); ecological ethics/issues (3); environmental and human rights practices in organizations (1); human rights (1); sustainable development with specific emphasis on environmental impact (1); balancing environmental and developmental objectives (1) [total: 12].

- Macro-level total: 26 of which 46\% concern environmental and human rights issues and 35\% the economic system.

Meso-level challenges/issues

- Business and society: including CSR (1) CSR and organizational culture to support it (1); ways to develop corporate culture conducive to integrity $(1)$; closing gap between professed ethics and practice (1); role of business in society $(1)$; governance issues in developing countries (1); governance of financial institutions (1) ethics and governance in small and medium enterprises (1); conflict of interest (1); disclosure (1); lack of clear guidelines on gifts, sponsorships and donations $(1)$; ethical issues relating to role/contribution of business to society (1); unethical business practice (e.g. fraud, corruption) (1) [total: 13].

Micro level challenges/issues

- Increased integration of Business Ethics into business practice (1); increased awareness and practice of codes of conduct by employees (1); whistle-blowing (1); executive greed and salaries (1); role of professionals (e.g. accountants) in ethics as professionals and in organizations (1); vetting of public servants (1) [total: 6].

Of the 45 issues mentioned above as challenges, 58\% relate to the macro-level; $29 \%$ to meso-level and $13 \%$ to microlevel. This suggest that the greatest challenges for Business Ethics are perceived to lie at the macro-level, especially in regard to the economic system and to ecology, followed by meso-level challenges, with little emphasis on the microlevel. At the macro-level there is greater agreement on the main themes and sub-themes, than at the meso- and micro-levels which reflect considerable diversity. Another noteworthy point is that only one respondent saw the development of teaching strategies for Business Ethics and communicating ethics to world leaders as a challenge. What is interesting is to compare the issues raised in this section with the results of the section on research/ publications. Comparatively little research dealt with the economic system or ecology yet here the challenges of the 
economic system represents $35 \%$ of the macro-level theme and ecology $46 \%$. On the other hand, considerable research/ publication has been done at the meso-level in areas like corporate governance and CSR which are also seen as the main challenges at this level. If we compare these findings to those in the section on focus areas in Business Ethics (4.3. above), we find that in the area of the greatest challenges there is little expertise or focus, with more at the meso- and micro-levels where fewer challenges are identified. These discrepancies between challenges perceived and focus and expertise in research and in the field itself, represent a challenge for the research community. Neither development of the academic field of Business Ethics, nor of meta-ethics is perceived as a challenge, nor has there been mention of the need to develop Business Ethics case studies for the region.

\section{CONCLUSION}

General conclusions are that 'Business Ethics' is the predominant term used to refer to the field of business and economic ethics, that most expertise is centered in South Africa, mainly in Gauteng, and the Western Cape, followed by the Eastern Cape, with 5 institutes/centres which are all in South Africa. Individual focus and expertise is mainly at the meso-level, followed by the micro-level, with less at macro-level or on Business Ethics as academic field. Institutional expertise is also mainly focused on the meso-level.

The main focus in training is on ethics at the meso- and micro-levels in the context of the organization. In teaching, at undergraduate level there is a fairly even balance between modules which provide theoretical foundations for Ethics, Business Ethics and Applied Ethics; and those which deal with ethical business issues on macro-, meso- and microlevels. As a single sub-theme, CSR and general Business Ethics modules seem to have the most compulsory taught modules at undergraduate level. At post-graduate level, most teaching centers on ethics at meso-level, especially CSR, corporate governance and ethics in relation to the corporation, with little focus on Business Ethics per se or on micro-level issues. Most research has been done in South Africa in CSR, corporate governance and economic justice/justice. It is concerning that there is little research being done specifically on Business Ethics as academic field. The greatest challenges for Business Ethics are perceived to be at the macro-level, especially in regard to the economic system and ecology, where there is little research, focus or expertise. This represents a challenge and opportunity for the research community in this field.

General recommendations would include greater collaboration by those in the field, especially in research, given the very small pool of resources and expertise in this region; greater collaboration, research and publication in the area of meta-ethics, Business Ethics as academic field and macro-level issues; development of case studies in and for the Southern African region, and a repeat survey of Business Ethics as academic field at a later date to investigate changes in the region especially in resources and as to whether there is greater research and expertise in the areas identified as the main challenges in this survey.

\section{ACKNOWLEDGEMENTS}

Research team members who assisted in this survey were Prof. M. E. Smurthwaite (sub-regional co-ordinator); Prof GJ Rossouw; $\mathrm{Mr}$ D Racionzer; Ms C Lalor; Dr P Omoyefa; Mr K Maepa.

\section{REFERENCES}

Barkhuysen, B. 1999. A survey of the current status of Business Ethics as an academic field in Africa. MA dissertation, Johannesburg: Rand Afrikaans University.

Barkhuysen, B. \& Rossouw, G. J. 2000. Business Ethics as academic field in Africa: its current status. Business Ethics: A European Review, 9(4): 229-235.

Milanzi, M. C. 1997. Business Ethics in Eastern and Southern Africa. Journal of Business Ethics, 16(14): 1549-1553.

Rossouw, G. J. 1997. Business Ethics in South Africa. Journal of Business Ethics, 16(14): 1539-1547

University of Botswana. [Online] Available: http://www.ub.bw/learning_ faculties.cfm?pid=795 [Accessed October,23, 2009]

Woermann, M. \& Hattingh, J. (unpublished but circulated in 2009). Guidelines for teaching Business Ethics: comparing experiences from South African universities. Stellenbosch: University of Stellenbosch, Department of Philosophy.

How to cite this article: Smurthwaite M. Business Ethics as field of training, teaching and research in Southern Africa. Afr J Bus Ethics 2011;5:81-8

Source of Support: Nil, Conflict of Interest: None declared

\section{AUTHOR}

Prof. Marilise Smurthwaite is Head of the Department of Applied Ethics at St Augustine College of South Africa, where she is an Associate Professor in Business Ethics. Her research areas include the corporation and economic justice in South Africa, Catholic Social Thought, especially as an ethical framework for examining the economy and related issues and ethical business leadership. Her publications include work on the purpose of the corporation, the unequal distribution of wealth in South Africa, executive remuneration, governance and Catholic Social teaching, moral responsibilities of leaders in various sectors, and ethics in banking. She was the sub-regional coordinator for Southern Africa for the Global Survey of Business Ethics. 
Reproduced with permission of the copyright owner. Further reproduction prohibited without permission. 